\title{
The necessity of a dual education system for Romanian automotive industry. Case study: The German dual vocational training
}

\author{
Ramona Pîrlog ${ }^{1, *}$, Ioan-Vlăduț Nuțu ${ }^{2}$, Anca Alexandra Purcărea ${ }^{1}$, and Aurelian Vlase ${ }^{2}$ \\ ${ }^{1}$ Politehnica University of Bucharest, Faculty of Entrepreneurship, Business Engineering and \\ Management, Bucharest, Romania \\ ${ }^{2}$ Politehnica University of Bucharest, Faculty of Engineering and Management of Technological \\ Systems - I.M.S.T., Bucharest, Romania
}

\begin{abstract}
According to the official data, Romania has more than 600 companies involved in the automotive industry, with more than 203,600 employees. However the automotive industry is facing a real problem when it comes to finding skilled work force. In the west part of the country, the unemployment rate is negative and companies are forced to find solutions for their lack of personnel. This study presents the solutions that were taken by Germany in order to solve the matter. A dual education system was implemented which combines trainings in a company with vocational education. This kind of system is practiced in countries such as: Germany, Austria, Switzerland and South Korea. As of 2005 young German people can learn one of 356 apprenticeship occupations through this program. In France, dual education has gained a lot of popularity since the 1990s. In order to gain more experience and have multilateral development, in Germany the students are also send to workshops run by guilds or chamber of commerce. The advantages of the dual training system are numerous and this program can help the industry by providing skilled workers with flexible qualifications, solution which may as well be suitable for the Romanian Automotive Industry.
\end{abstract}

\section{Introduction}

In recent years, the private sector showed a growing interest for a qualified and well trained work force with good technical skills. In the automotive sector, the counties in the West of the country are experiencing negative unemployment and the private companies are forced to find solutions for their lack of personnel.

Because of this shortage of human resources, companies are losing business and turnover. Representatives of car manufacturers in Romania consider that the scarcity of trained personnel is due to the migration of the well trained work force to more developed markets in Western Europe or the Middle East. The significant increase in investments in

${ }^{*}$ Corresponding author: ramona.pirlog@gmail.com 
new facilities and distribution service is not directly proportional to the increase number of specialists, which leads to a lack of personnel. [1]

A relatively new trend for Romania is recruiting students in the final years or recent graduates and offer them numerous specialized trainings through their own education centers. However, this approach is suitable for the large companies, the small and medium size enterprises have difficulties in finding the skilled workers.

\section{Consideration regarding the Dual Education System}

The main objective of vocational training: to produce skilled workers with flexible qualifications who are mobile and capable of working in their chosen fields.

According to the International Centre for Technical and Vocational Education and Training (UNESCO-UNEVO) the Dual Education System is called "dual" because it combines apprenticeships in a company and vocational education at a vocational school in one course. In the company, the apprentice receives practical training which is supplemented by theoretical instruction in the vocational school.

The European Centre for the Development of Vocational Training CEDEFOP adds that the dual education system combines periods in an educational institution or training center and in the workplace. The scheme's alternation can take place on a weekly, monthly or yearly basis. Depending on the country and applicable status, participants may be contractually linked to the employer and/or receive a remuneration. [2]

This system is practiced in several countries, notably Germany, Austria, Hungary, Bosnia and Herzegovina, Croatia, Serbia, Slovenia, Macedonia, Montenegro and Switzerland, but also Portugal, Denmark, the Netherlands, France, Australia and Egypt, and for some years now in China and other countries in Asia.

The German Dual Education System is one of the cornerstones of the successful brand 'Made in Germany' due to which a small nation of only 80 million people is able to be the world champion in exports for several years. The system is widely practiced in Germany for over 350 officially-recognized training occupations. [3]

In 2011 , about $68 \%$ of all apprentices received an employment contract after completing their training. Almost 1.4 million young people are currently on a vocational training course in Germany accordingly to the economic development agency of the Federal Republic of Germany, The Germany Trade \& Invest (GTAI). [4]

Germany has Europe's lowest youth unemployment rate, has thereby increased the competitiveness of Germany's economy and enjoys an excellent reputation as a result of the dual system. [5]

As stated by the Indo-German Training Center, the main features of a dual education system are:

- Joint educational responsibility meaning that the training institution and the private companies work together in order to create a unique synergy between learning and working. It also leads to a constant modernizing of the curricula and guarantees an up-to-date learning that follows the developments of the economy.

- Practice integration. Theory imparted in the classroom is complimented with hands-on experience at the workplace, so that real-life situations immediately test the effectiveness of classroom theory and vice versa. The system seeks to impart structured knowledge and active competence, in their proper context.

- Best future perspectives. In choosing the dual system, the student chooses a safe future. $100 \%$ of the students receive a job placement immediately after completion of the program. 
In 2012 was launched the dual education programmer at Kecskemet College in Hungary for 25 vehicle engineer students in partnership with Mercedes-Benz Manufacturing Hungary and Knorr-Bremse Fékrendszerek Kft and the dean of the college stated that "these students are the drivers of the labor market as their achievements are significantly better than those of regular students". [6]

\section{Costs and Benefits of the Dual Educational System}

„The costs of the dual educational system are shared by regional governments, private companies, and the apprentices themselves. The government pays for the costs of the public education side of training, which amounts to about one percent of the country's gross domestic product" [4], while the companies pay for all of the costs associated with the onthe-job training.

As a result from a survey did by the Federal Statistical Office in 2013, the annual net costs for companies per apprentice (2007) in Germany was 3.596 euros. However the companies will receive engineers with working experience and commitment towards the company by the end of the training. [7]

As shown in figure 1 the apprentice receives practical training in the company for three or four days which is supplemented by theoretical instruction in the vocational school for another day or two.

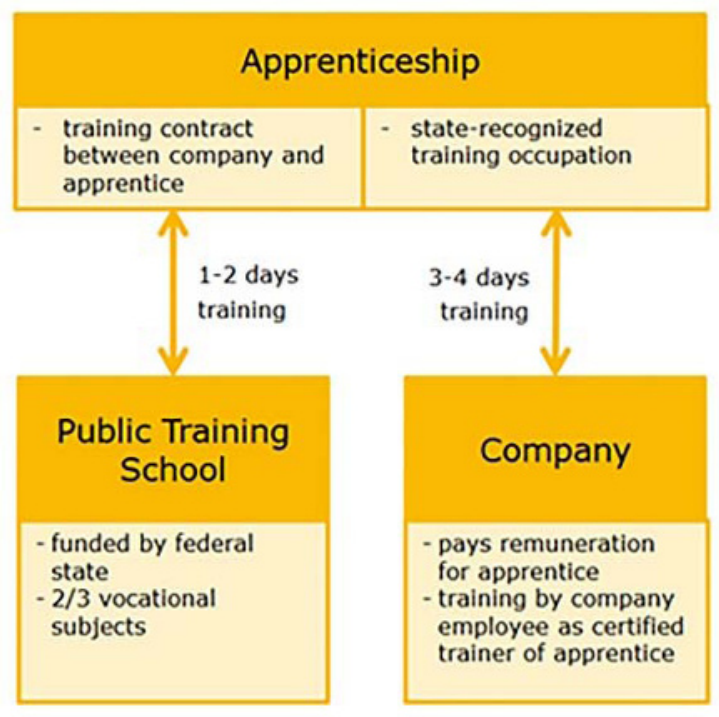

Fig. 1. Dual System of Apprenticeship. [7]

Prof. Dr. Dieter Euler states the following benefits of the dual education system:

- Training is designed to meet the practical needs of the labor market

- Occupational skills enable individuals to work in their chosen fields

- Skills are applicable to a wide range of settings within the field, which allows individuals to be flexibly employed in a variety of businesses

- Skill profile makes trained workers more mobile

- In some cases skills are developed in a fixed process, without separate steps or interruptions

- Skill development may in some cases be combined with aspects of career and occupational development 
- A responsible agency (usually the chamber of commerce or crafts) administers a centralized examination to assess trainees' skills, adhering to the principle that the teacher and the examiner should not be one and the same

- Benefits: skills enhance workers' flexibility and mobility, reduce the danger of social marginalization and raise educational levels in a non-academic context

In figure 2 it is shown the supply and demand in the dual training employment in Germany between 1995 and 2011.

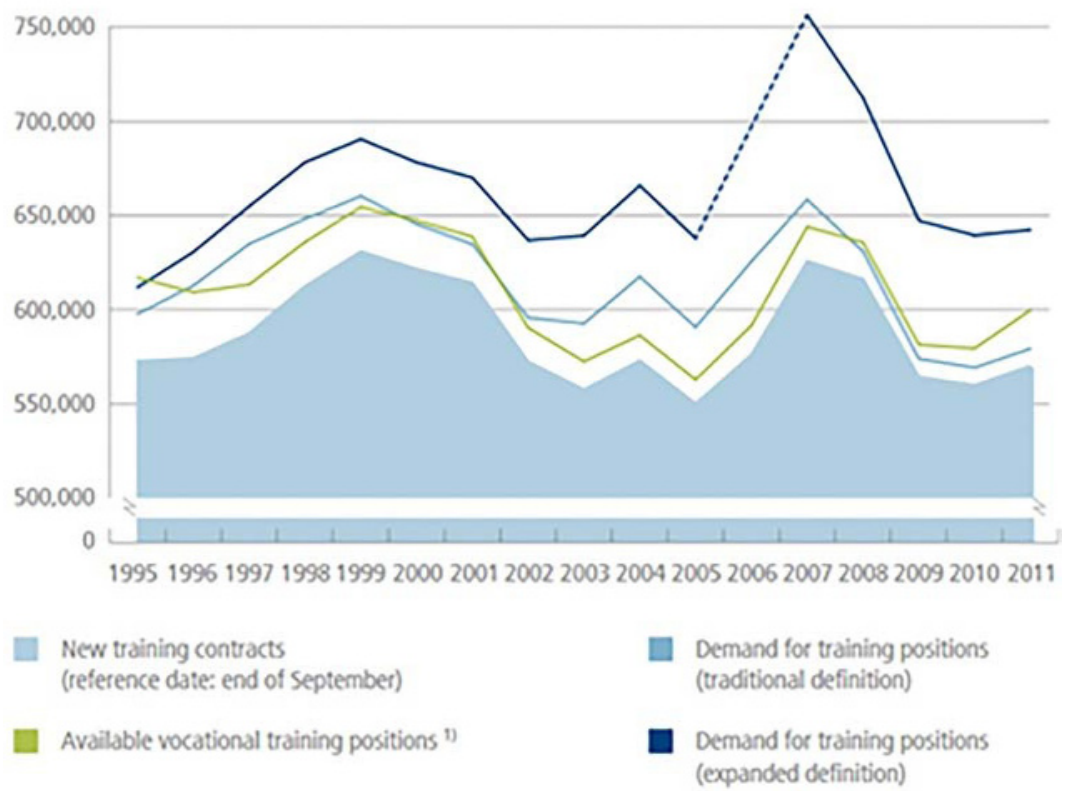

Fig. 2. Supply and demand in training in Germany 1995-2011. [8]

The Federal Institute for Vocational Education and Training (BIBB) conducted a survey in 2004 in order to establish the reasons that drove the companies to take part in dual education and 94\% responded that ,trainees fit company's needs”, 93\% said that „acquisition of specialists was not available on labor market” and $72 \%$ consider this kind of program as a ,possibility to choose best candidate when considering employment after end of apprenticeship".

\section{Automotive Industry in Romania}

According to the official data, Romania has more than 600 companies involved in the automotive industry, with 203,600 employees. Approx. 20\% of all Romanian exports are from the automotive industry.

The total turnover of the automotive industry in 2014 was estimated to 18 billion Euro, a 7\% increase from 2013. [6] As regards the turnover of the automotive parts sector, it increased by $8.7 \%$ in 2014 as compared to 2013 . The entire automotive industry is estimated to have contributed around $12 \%$ to the Romanian GDP in 2014. The main drivers of this sector remain the Renault Group via the international "entry" program and the export of components, directly or through integrators.

In 2015, the Romanian automotive industry showed a solid, steady growth. According to the estimates of the Association of Automotive Manufacturers of Romania (ACAROM) 
in the first 5 months of 2015 , automotive production increased by $9 \%$, the export being $1.2 \%$ lower than in the same period of last year. Internal automotive sales increased by $35 \%$, while the ratio of second hand cars vs. new cars produced domestically and sold in Romania is 7.3/1 (the average age of second hand cars is 10.6 years). The Association of Automotive Manufactures of Romania - ACAROM is a professional body of companies involved in the automotive industry, associated in order to represent the interests of the automotive sector. ACAROM, a non-profit organization, has 144 members and was set up in 1996. [6]

In figure 3 it is presented the evolution in turnover for automotive companies, both for automobiles and spare parts. In 2014, the turnover was 13\% more than in 2013.

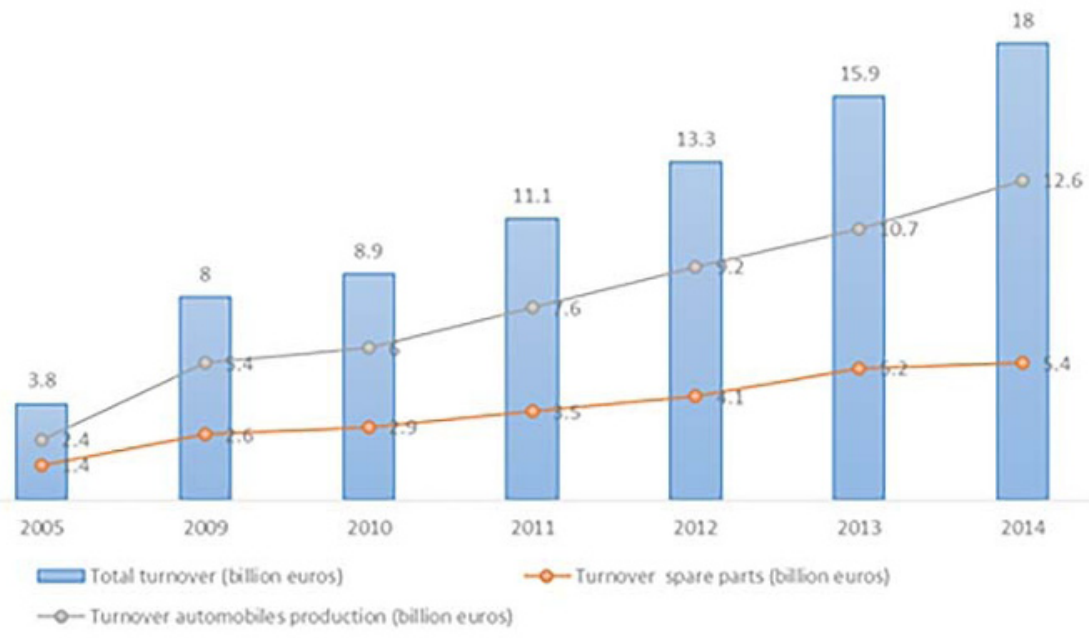

Fig. 3. Turnover for automotive industry in Romania 2005-2014. [6]

The Association of Automotive Manufactures of Romania ACAROM represents the interests of more than 150 companies from the automotive industry. In the last years they tried to be the connection between the private sector and government. Among their requests there is one regarding human resources. The private companies are asking for the following : a) developing partnerships between public educational institutions and private employers to better prepare students, b)equipping school laboratories with modern and up to date equipment, c) initiate training courses for the automotive industry, d) the need to review the study programs taking into account the requirements of the industrial environment and advances in the field of high technologies, e) he need for review of educational material in order to fold the requirements of employers, f) Improvement in terms of quality, quantity and skill set developed by the educational system in Romania in certain professional fields.

\section{Conclusions}

At the meetings of the automotive industry associations, the representatives of the companies involved in car manufacturing or auto parts are asking the Ministry of Education to implement a dual education system. The involved parties see this system as a solution to the lack of well trained personnel. The charts presented above show that the automotive industry is in a constantly development in our country thus requiring work force. The main advantage of the program is that the student starts as an entry-level employee who can take tasks according to his growing abilities and at the end of the program, the company will 
have an employee who already knows the workflow and who, during a considerable amount of time, has benefited from the experience of more experienced co-workers. The student also has his share of benefits by earning money from the beginning and not after exams.

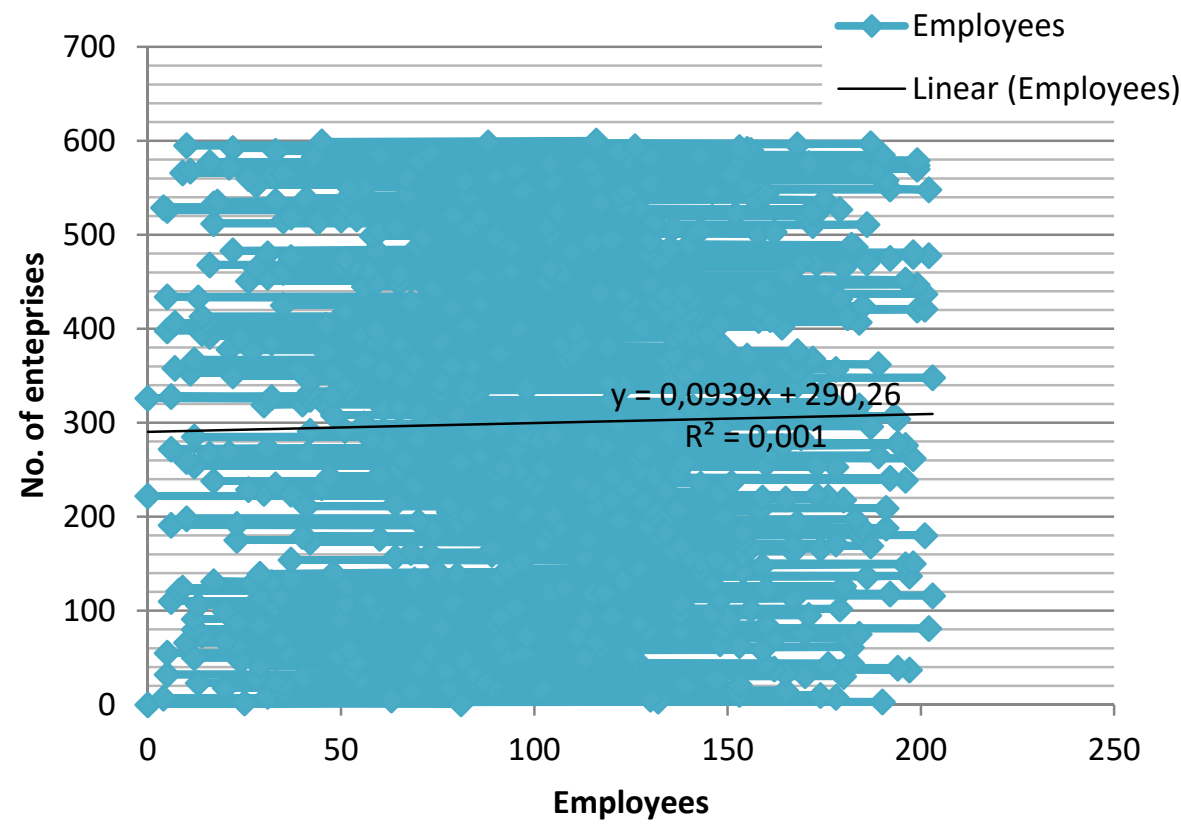

Fig. 4. Romanian enterprises versus number of employees.

As we can see although there is a lack of highly skilled personnel in the Romanian enterprises (over 600) the trend is ascending as more and more students are applying to these companies as they are more involved and invest constantly in skills hunting strategies. Thus we see that educational dual systems strategies pay off in long term projects.

The success of the German dual educational system has understandably attracted much attention from many other industrial nations. However the acceptance is affected by economic, social and pedagogical aspects, as well as by the cultural setting, which we will turn to now.

In general, it can be stated that the acceptance of vocational training in countries with a high level of dual vocational training is higher than in those countries in which dual vocational training does not exist at all or only exists to a very limited degree.

\section{References}

1. C. Wieland, E. Lezcano, (2016)

2. D. Euler, Bertelsmann Stiftung (2013)

3. Germany Trade \& Invest (2014)

4. Clark, Charles S. "Youth Apprenticeships." The CQ Researcher (1992)

5. J. Petrosky (1996)

6. ACAROM research and studies (2013-2016)

7. Germany Trade \& Invest (GTAI) - http://www.gtai.de

8. AutorengruppeBildungsberichterstattung (2012) 